\title{
A CLOSED FORM SOLUTION FOR PREDICTING SPRINGBACK IN BENDING OF BEAMS INCLUDING HARDENING EFFECT
}

\author{
A. López Castro, J.F. Durodola* and N.A. Fellows \\ School of Technology, Oxford Brookes University, \\ Wheatley Campus, Wheatley, Oxon OX33 1HX, U.K. \\ *(Corresponding author: E-mail: jdurodola@brookes.ac.uk)
}

\begin{abstract}
Springback is an implicit phenomenon in most forming processes and needs to be accounted for in the design of forming tools. This is essential in order to limit the number of iterations required during the design and fabrication of forming tools and dies. This work presents a closed form solution for predicting springback in bending including hardening effect. Springback was also determined using experimental testing. The results obtained are compared with analytical results and the influence of hardening on springback is analysed.
\end{abstract}

\section{INTRODUCTION}

Sheet metal forming is one of the most important manufacturing processes for mass production in industry. Several sheet-forming processes include bending. In these processes, plastic deformation is followed by some elastic recovery upon unloading. This change in shape is known as springback and its extent depends on material properties, geometry and tooling dimensions. Springback can be particularly significant in structures, panels and components formed into large radii.

Springback results in the deviation of a component from a desired shape after the forming load is removed. This means that additional geometric adjustments have to be made to account for it in the design of forming tools and dies. The phenomenon has been analysed using different procedures over the last few decades. Early works by researchers developed correction curves using empirical relations based on experimental testing [1-2]. Many analytical solutions have subsequently been derived [3-6]. A good review of these previous works can be found in references [7-9]. Other workers have used the finite element method [10-11].

The earliest attempt to find an analytical solution for springback correction was started by Sturm and Fletcher [3] in the aircraft industry in the early 1940s. The solution developed was however cumbersome to apply. It requires explicit determination of distances from the neutral plane to beam surfaces as well as surface stresses. Schroeder [5] presented another analytical solution in 1943 but this was also rather complex to implement. It was not until the late 1950 s when by examining narrow beams of an elastic-perfectly plastic material that Gardiner [6] developed a solution for determining springback after bending that was far simpler to use. Gardiner's formula has been embraced by the metals forming community for decades as a very good approximation for the calculation of springback.

As highlighted in the foregoing, Gardiner's solution assumes elastic perfectly plastic material behaviour. Most engineering materials however exhibit strain hardening with significant increase in strength in the post yield regime. It will therefore be helpful to obtain a more general and accurate closed form equation for predicting springback that account for this factor. This work presents a closed form solution for predicting springback in bending including hardening effect. Springback was also determined by experimental testing and the results obtained are compared with analytical results. The effect of hardening is discussed in the light of the results obtained. 


\section{SPRINGBACK PREDICTION IN BENDING INCLUDING HARDENING EFFECT IN BEAMS}

Suppose a beam is subjected to bending, it is possible to obtain its radius of curvature if the surface strain and thickness of the specimen are known. The radius of curvature after loading and unloading can be obtained using Eq. 1 and Eq. 2.

$$
\begin{aligned}
& R_{o}=\frac{h}{2 \varepsilon_{o}} \\
& R_{f}=\frac{h}{2 \varepsilon_{F}}
\end{aligned}
$$

where $h$ is the depth of the beam and $\varepsilon_{o}$ and $\varepsilon_{f}$ are the surface strains on loading and unloading states respectively. The radii of curvature can also be determined by using Eq. 3 .

$$
R=\frac{\left(X_{c}^{2}+\delta^{2}\right)}{2 \delta}
$$

where $\delta$ is the deflection at the middle of the beam and $X_{c}$ is the distance from the centre of the beam to the outer support point in the case of a four point bend loading configuration. The difference between $\delta$ corresponding to loading and unloading gives the springback.

The external moment $M$ is equal to the internal moment [12] which is given by Eq. 4 .

$$
M=2 \int_{0}^{h / 2} \sigma b y d y
$$

Let the surface strain after bending be $\varepsilon_{1}$ as illustrated in Figure 1. The figure also illustrates the stress distribution across the depth of the beam for a general material with hardening behaviour.

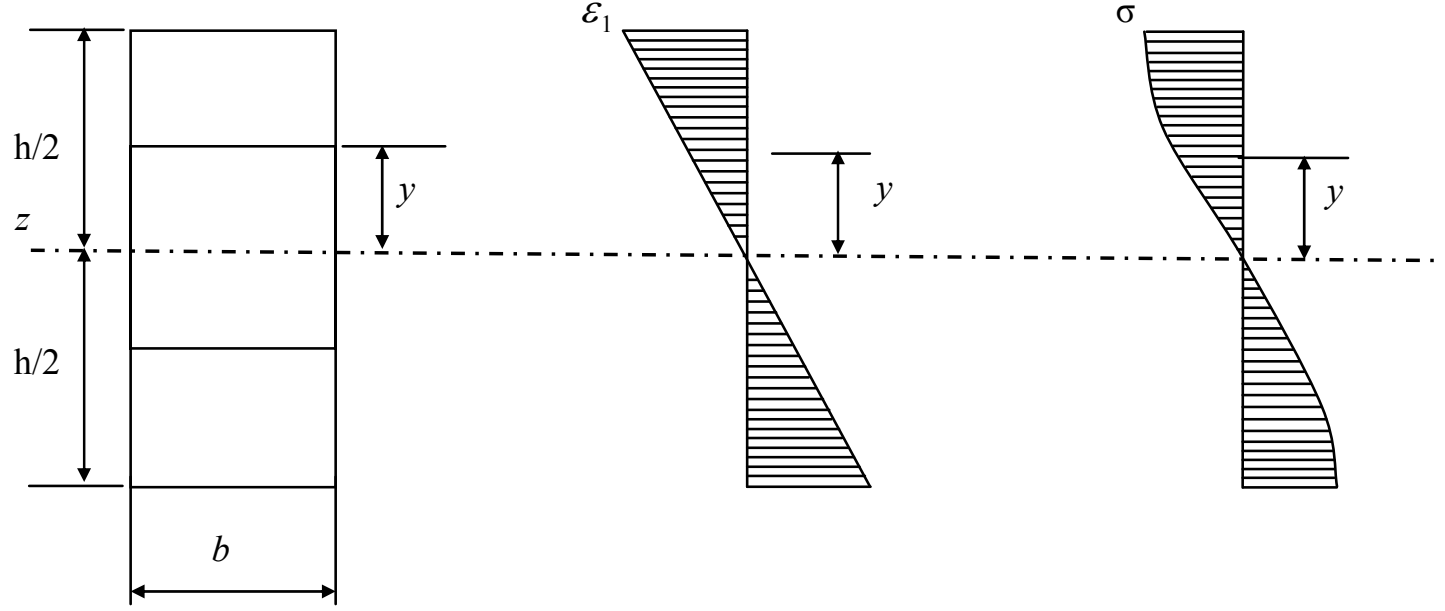

Figure 2. Strain and Stress Distribution Across the Depth of a Beam with Hardening Behaviour 
By transforming from the independent variable $y$ to strain $\varepsilon$ we have from Figure 2 $y=h \varepsilon /\left(2 \varepsilon_{1}\right)$ and $d y=h d \varepsilon /\left(2 \varepsilon_{1}\right)$. Eq. 4 can now be written as Eq. 5:

$M=\frac{b h^{2}}{2 \varepsilon_{1}^{2}} \int_{0}^{\epsilon_{1}} \sigma \varepsilon d \varepsilon$

Let the stress strain for a general material behaviour be represented by a form of the Ludwik equation [13] as given in Eq. 6 below.

$\sigma=\left\{\begin{array}{lcc}E \varepsilon & & \varepsilon \leq \varepsilon_{y} \\ Y & \text { for } & \varepsilon_{y}<\varepsilon \leq \varepsilon_{t} \\ K \varepsilon^{n} & & \varepsilon_{t} \leq \varepsilon \leq \varepsilon_{1}\end{array}\right.$

Then the moment can be re-written as:

$M=\frac{b h^{2}}{2 \varepsilon_{1}^{2}}\left[\int_{0}^{\epsilon_{y}}(E \varepsilon) \varepsilon d \varepsilon+\int_{\epsilon_{y}}^{\epsilon_{t}} Y \varepsilon d \varepsilon+\int_{\varepsilon_{t}}^{\varepsilon_{1}}\left(K \varepsilon^{n}\right) \varepsilon d \varepsilon\right]$

By using $\varepsilon_{y}=Y / E, \varepsilon_{1}=h /(2 R)$ and simplifying Eq. 7 we have Eq. 8

$M=2 b R^{2} E\left[-\frac{1}{6}\left(\frac{Y}{E}\right)^{3}+\frac{1}{2}\left(\frac{Y}{E}\right) \varepsilon_{t}^{2}+\frac{K}{(n+2) E}\left(\frac{h}{2 R}\right)^{n+2}-\frac{K}{(n+2) E} \varepsilon_{t}^{n+2}\right]$

where $\varepsilon_{\mathrm{t}}$ is strain at the end of the yield transition zone. The moment due to springback is also obtained from the relationship $M=E I\left(1 / R_{E}\right)$ where $E$ is the Young's modulus of the material, I is the second moment of area and $\left(1 / R_{E}\right)$ is the change in curvature. This gives Eq. 9 for a rectangular section.

$M=E \frac{b h^{3}}{12}\left(\frac{1}{R}-\frac{1}{R_{F}}\right)$

Equating Eqs. 8 and 9 and simplifying gives the ratio of the initial radius, $R$, to the final springback radius as in Eq. 10.

$\frac{R}{R_{F}}=\frac{24 K_{E} R_{h}^{3}}{n+2}\left(\varepsilon_{E}^{n+2}-h_{R}^{n+2}\right)+4\left(R_{h} Y_{E}\right)^{3}-12 R_{h}^{3} Y_{E} \varepsilon_{t}^{2}+1$ 
Where $K_{E}=K / E, R_{h}=R / h, Y_{E}=Y / E$ and $h_{R}=h /(2 R)$. Eq. 10 can be shown for $K=Y$ and $\mathrm{n}=0$ and $\varepsilon_{\mathrm{t}}$ equal to strain at first yield (Y/E) to reduce to Eq. 11, which is the elastic perfectly plastic solution derived by Gardiner [6]. For materials such as the EN3B $3 \mathrm{~mm}$ thick given in Figure 2, there is no yield transition zone therefore $\varepsilon_{t}$ is also equal to strain at first yield i.e. (Y/E).

$$
\frac{R}{R_{F}}=4\left(\frac{R Y}{E h}\right)^{3}-3\left(\frac{R Y}{E h}\right)+1
$$

Eq. 11, together with the knowledge of the dimensions and the properties of the material, i.e. $h, E$ and $\mathrm{Y}$ and the initial radius of curvature, $R$, can be used to find the final radius $R_{F}$.

The limitations of the equations derived in this paper lie primarily in the assumptions of the underlining theory. The theory assumes that the strain at any point in the beam is proportional to the distance of the point from the neutral axis. This assumption holds provided that the cross-sectional dimensions of the beam are much smaller than the radius of curvature [14], typically less than onetenth. It should be noted that none of the bending analysis considered in this work exceeded 5\% surface strain on the beams. Beyond this limit anti-clastic effect becomes pronounced.

\section{MATERIAL}

Beams with thicknesses of 1, 3 and $5 \mathrm{~mm}$ made of two different materials, CR4 and EN3B steels were tested. All the specimens were annealed in order to relieve any previous residual stresses caused by processing and fabrication. The effects of oxidation were reduced by placing the specimens in a steel foil jacket and wrapped closely to expel air. The annealing was carried out at $660{ }^{\circ} \mathrm{C}$ for one hour. The annealing carried out eliminated the need to consider residual stress and Bauschinger effects in the analytical formulation.

Table 1 gives a summary of the Young's modulus E, yield strength $\sigma_{\mathrm{y}}$, and the hardening strength and exponent $K$ and $n$ respectively for the materials. The hardening strength and exponent were determined from the stress strain curves according to ASTM standards [12]. The strain ranges considered were between the end of the yield transition zone and the ultimate tensile strength. This applied particularly to the EN3B $5 \mathrm{~mm}$ thick and CR4 $1 \mathrm{~mm}$ thick materials that have long yield transition zones as can be seen in Figure 1.

The constants $K$ and $n$ in equation were determined from simple graphical data processing of the stress strain curve for the material of interest. This was done by plotting $\log \sigma$ against $\log \varepsilon$. The slope of the resulting line gives $n$ and the intercept is $\log K$ from which $K$ can then be found. The value of $n$ varies between 0 and 1 for real materials. The values of elastic and hardening properties for the materials used are summarised in Table 1.

Table 1. Summary of the Properties of the Materials Used for Springback Tests in Bending

\begin{tabular}{|l|l|l|l|l|l|l|l|}
\hline Material & Thickness & $\mathrm{E}(\mathrm{GPa})$ & $\mathrm{Y}(\mathrm{MPa})$ & $\varepsilon_{\mathrm{y}}$ & $\varepsilon_{\mathrm{t}}$ & $\mathrm{K}(\mathrm{MPa})$ & $\mathrm{n}$ \\
\hline CR-4 & $1 \mathrm{~mm}$ & 211 & 250 & 0.0011848 & 0.02699 & 413 & 0.1282 \\
\hline EN-3B & $3 \mathrm{~mm}$ & 190 & 450 & 0.00225 & 0.00858 & 708 & 0.0764 \\
\hline EN-3B & $5 \mathrm{~mm}$ & 195 & 320 & 0.00164 & 0.02636 & 588 & 0.1530 \\
\hline
\end{tabular}




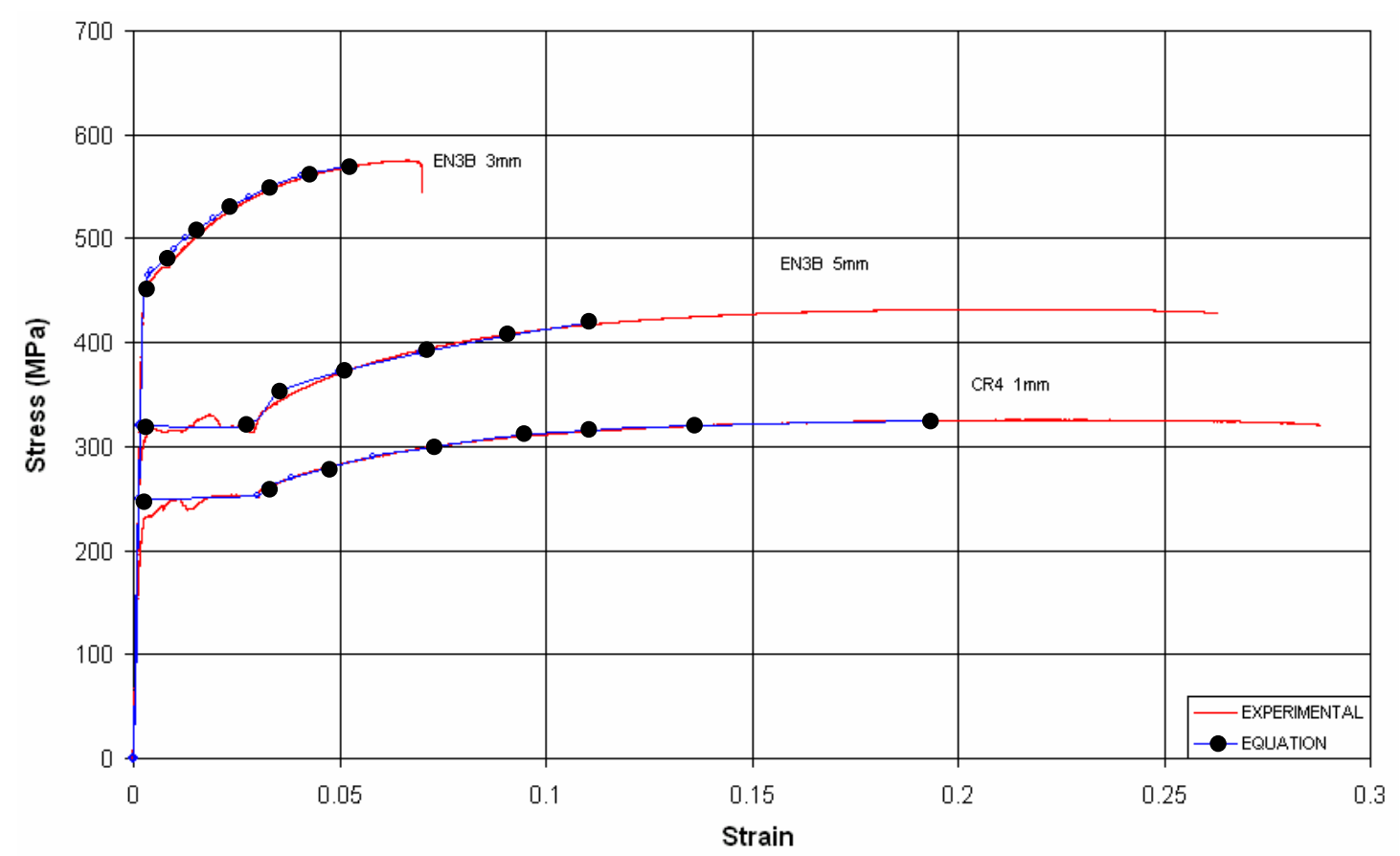

Figure 2. Stress-strain Graphs for the Materials Considered Compared with Those Obtained Using the Material Models in Eq. 6 and K and n Properties Given in Table 1

\section{EXPERIMENTAL PROCEDURE FOR THE BEND TESTS}

The beams were tested in a four point bending configuration. The internal and external support distances of the four point bend rig were 100 and $200 \mathrm{~mm}$ respectively. The beams were nominally loaded to $25 \mathrm{~mm}$ deflection which led to plastic deformation in all the beams.

The bending tests were carried out using displacement control. The loading and unloading rate was $0.03 \mathrm{~mm} / \mathrm{sec}$ up to the maximum deflection desired. The specimens were loaded at the maximum deflection for a period of $30 \mathrm{sec}$ and then unloaded at the same rate as for the loading. After bending, the load was released to enable springback to take place. An LVDT was used to determine the deflection during loading and unloading.

\section{RESULTS}

This section presents the effects of elastic plastic and hardening material behaviour models on the prediction of the springback and on springback ratio $\mathrm{R} / \mathrm{R}_{\mathrm{F}}$. However, the effect of these material models on beam response to loading are considered first. The results of experimental tests carried out are also compared with predictions for springback based on the material models. Details are included to assist with the explanation of the observations made. The properties of the materials used in the analyses are as given in Table 1. 


\subsection{Predicted Effect of Material Models on Beam Response and Springback Ratio}

The stress strain curve for the EN3B $3 \mathrm{~mm}$ material lends itself to ease of use for comparison of prediction of the effect of hardening using Eqs. 10 and 11. It is helpful to first compare the moments developed based on elastic perfectly plastic and hardening material behaviours. The moments are normalised by dividing by flexural stiffness $E I$, where $E$ is Young's modulus and $I$ is second moment of area. The results are presented in Figure 3 against different extents of surface strain during bending. The difference between results for both is compared in percentage relative to that of the hardening behaviour also in Figure 3. The difference between both moments can be seen to increase with increasing load or surface strain as to be expected.

Figure 4 shows the prediction of springback ratio $R / R_{F}$ against $R / h$. The prediction based on elastic perfectly plastic behaviour is very similar to that of the hardening behaviour and can hardly be differentiated in a plot of both results. The figure shows the difference to vary from about $-8 \%$ to $4 \%$ relative to the prediction based on the hardening model. This difference is relatively low compared to the difference seen in the values of moments for a given level of surface strain. This apparent anomaly can be explained by expressing the difference in springback ratios in terms of the moment based on the two material models. This is given by Eq. 12 .

$\left(\frac{R}{R_{f}}\right)_{h}-\left(\frac{R}{R_{f}}\right)_{e p}=\frac{R \Delta M}{E I}$

where subscripts $h$ and ep are used to denote hardening and elastic perfectly plastic material behaviour models. The term on the right hand side of Eq. 12 is a product of two components $R$ and $\Delta M$ that vary inversely as surface strain increases. Whereas $\Delta M$ increases as surface strain increases, $R$ decreases. This implies that increasing value of the moment does not necessarily translate to high values in $R_{F}$.

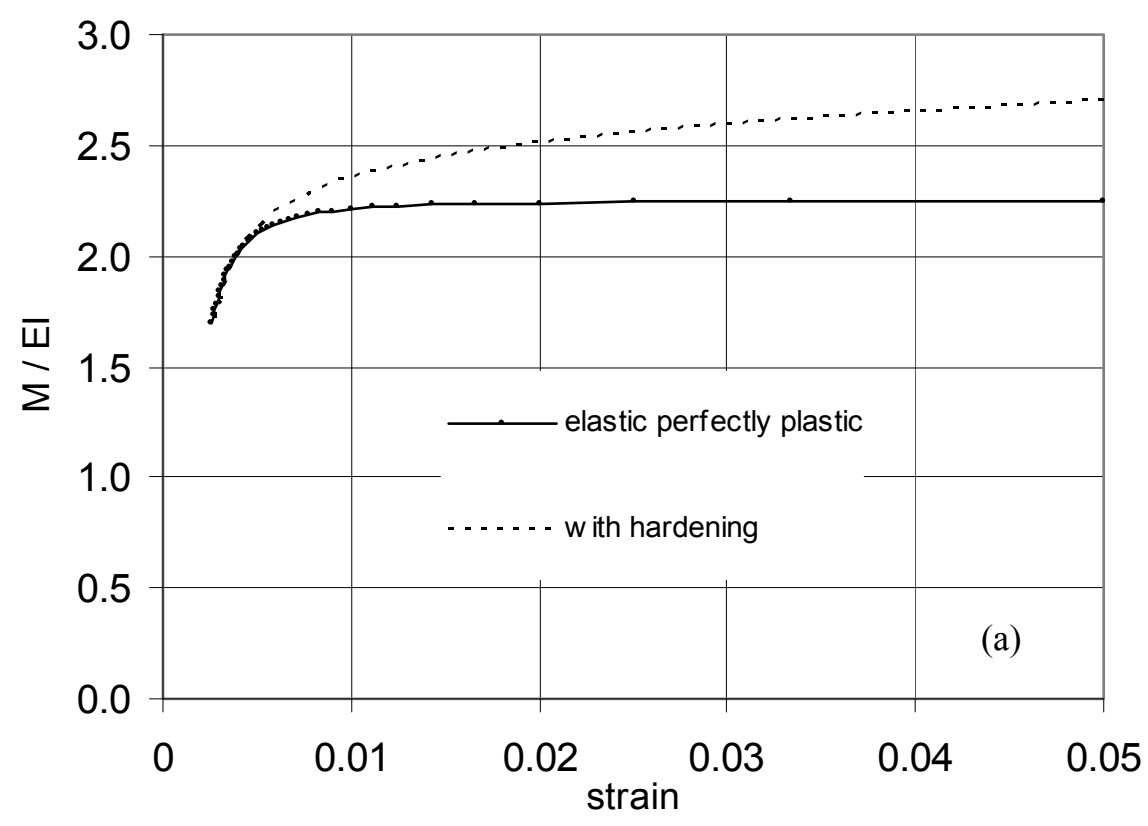




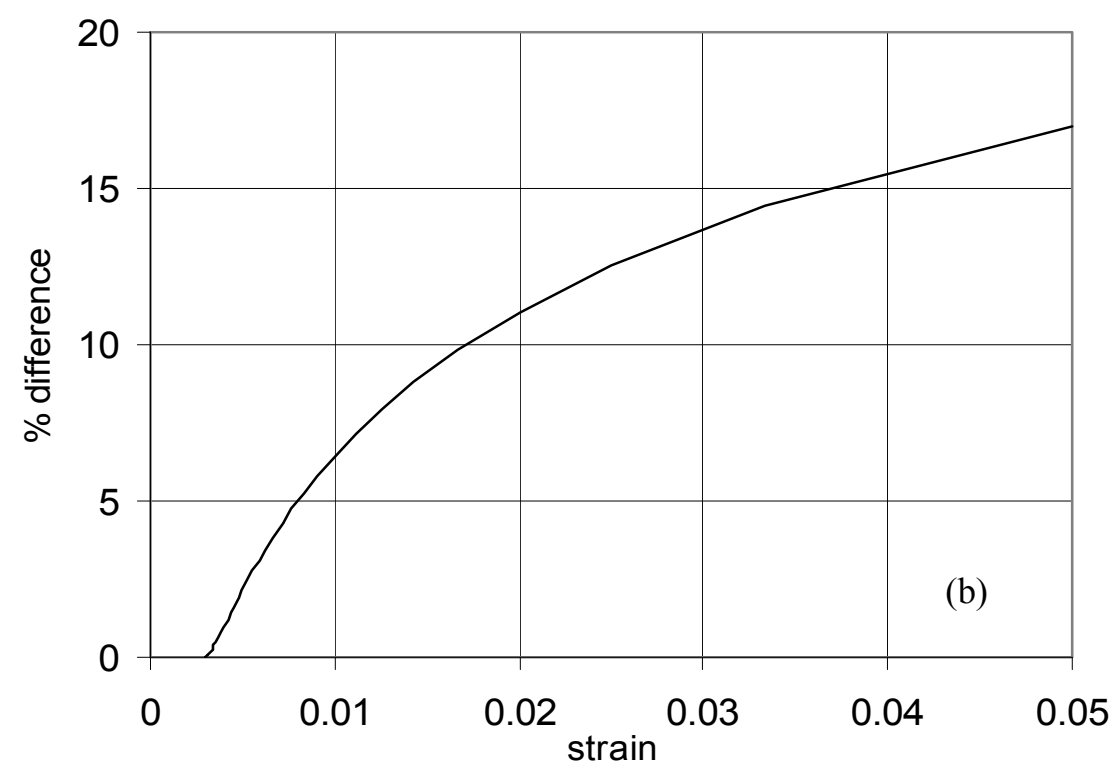

Figure 3. The Plot of Comparison of Results of Elastic Plastic and Hardening Material Models with Increasing Loading or Surface Strain for (a) Normalised Moments and (b) Percentage Difference Between the Moments

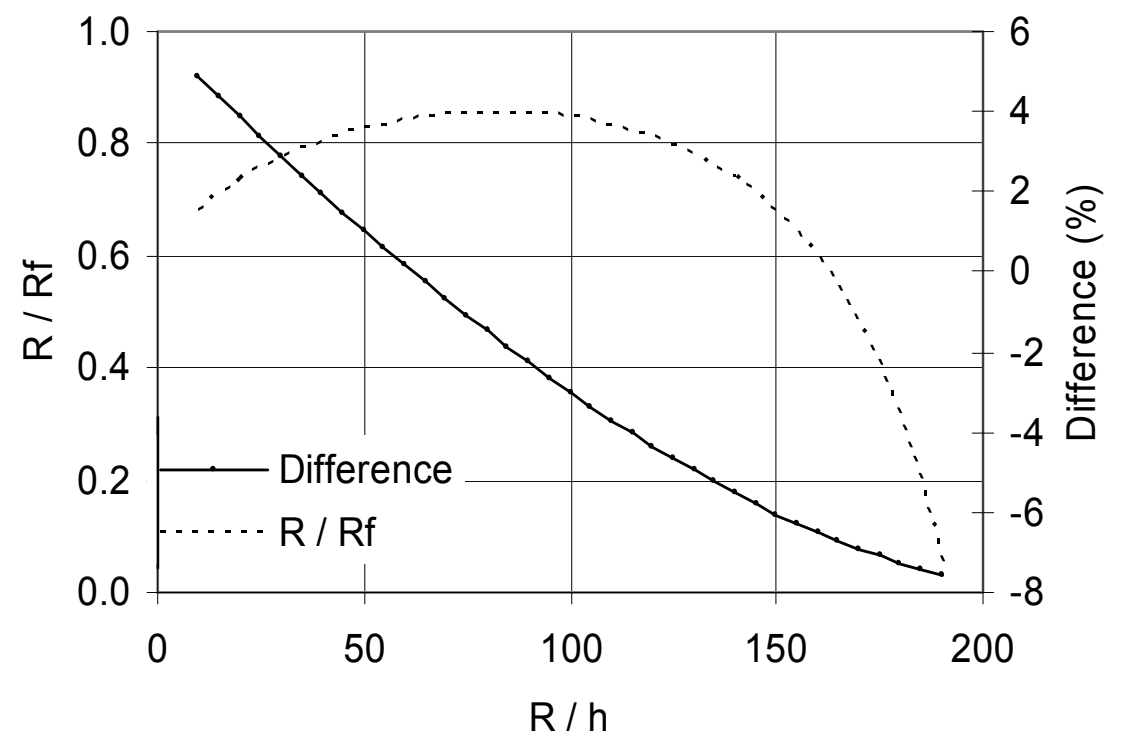

Figure 4. Prediction of Springback Ratio Using the Hardening Equation for EN3B $3 \mathrm{~mm}$ Thick

\section{COMPARISON OF PREDICTED SPRINBACK RATIO WITH EXPERIMENTAL RESULTS}

The main aim of this paper is to test the new general solution presented in this work for material behaviour for springback in beams using theoretical and experimental analyses. Three sets of tests were carried out on specimens with thicknesses of $1,1.5$ and $3 \mathrm{~mm}$.

The radius of curvature obtained using Eq. 11 based on deflection after loading and unloading and taking ratios is plotted in Figure 5 for the three materials considered. Three experimental test results are also plotted in the figure and shows good agreement. Table 2 also shows comparison of experimental and prediction for springback using the hardening equation. 


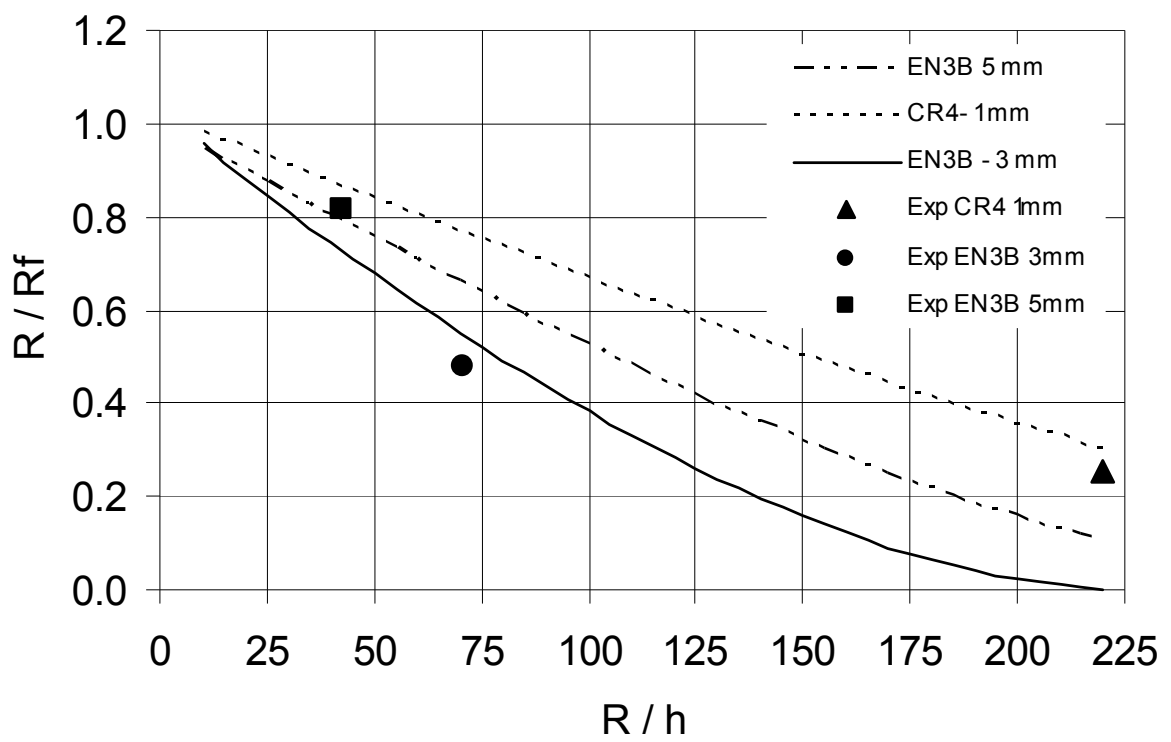

Figure 5. Prediction of Springback Ratio Using the Hardening Equation and Experimental Results

As results in Table 2 show, both Gardiner's solution and the new solution give same results for the CR-4 and EN-3B $5 \mathrm{~mm}$ thick materials. In these cases, the surface strains were below the yield transition strain limit. This means that the materials were still in the elastic perfectly plastic range. Hence the two solution methods being the same in this state gave the same prediction. The results are however different for the EN-3B $3 \mathrm{~mm}$ material that exhibits negligible yield transition strain and the surface strain extends into the hardening stage. In this case the new solution is about 5\% more accurate compared to the experimental result. It can also be observed from Figure 5 that springback increases with increasing yield strength, thickness and curvature. This is in agreement with work previously reported by other authors $[7,11]$.

Table 2. Comparison of Predicted and Experimental Results for Springback

\begin{tabular}{|l|l|l|l|l|l|l|l|}
\hline Material & $\begin{array}{l}\text { Thickness } \\
(\mathrm{mm})\end{array}$ & $\begin{array}{l}\text { Surface } \\
\text { strain after } \\
\text { bending }\end{array}$ & $\begin{array}{l}\text { Experi- } \\
\text { mental } \\
(\mathrm{mm})\end{array}$ & $\begin{array}{l}\text { Predicted } \\
\text { Gardiner } \\
(\mathrm{mm})\end{array}$ & $\begin{array}{l}\text { Predicted } \\
\text { New } \\
(\mathrm{mm})\end{array}$ & $\begin{array}{l}\text { Error } \\
\text { Gardiner } \\
(\%)\end{array}$ & $\begin{array}{l}\text { Error } \\
\text { New } \\
(\%)\end{array}$ \\
\hline CR-4 & 1 & 0.0023 & 18.2 & 17.7 & 17.7 & -2.7 & -2.7 \\
\hline EN-3B & 3 & 0.0071 & 13.6 & 12.1 & 12.7 & -11.0 & -6.6 \\
\hline EN-3B & 5 & 0.0118 & 5.1 & 5.6 & 5.6 & 9.8 & 9.8 \\
\hline
\end{tabular}

\section{CONCLUSIONS}

An equation for predicting springback in bending including the effect of hardening has been presented. For a given bend radius $R$, the new equation presented provides a means to predict the springback radius $R_{F}$ more accurately for a general non-linear material behaviour than the existing elastic perfectly plastic solution. However, although the result of the analyses carried out shows that hardening increases the moment required for forming the materials considered, it also shows that this does not translate proportionally to as much change in springback ratio. Experimental results obtained show good agreement generally with the predictions made for springback especially in the case where the material deformed beyond the yield transition strain into the hardening regime. 


\section{ACKNOWLEDGEMENTS}

A López Castro will like to acknowledge the support of the Mexican Government through CONACyT, for his scholarship.

\section{REFERENCES}

[1] Chapman, F.B., Hazlett, T.H. and Schroeder, W.M., "Springback in Flanging", Product Engineering, 1942, Vol. 13, pp. 382-383.

[2] Carden, W.D., Geng, L.M., Matlock, D.K. and Wagoner, R.H., "Measurement of Springback", International Journal of Mechanical Sciences, 2002, Vol. 44, pp. 79-101.

[3] Sturm, R.G. and Fletcher, B.J., "Determining Springback-I”, Product Engineering, Oct. 1941, pp. 526-528.

[4] Sturm, R.G. and Fletcher, B.J., "Determining Springback-II", Product Engineering, Nov. 1941, pp. 590-594.

[5] Schroedes, W., "Mechanics of Sheet-Metal Bending", Transaction of ASME, Nov. 1943, pp. 817-827.

[6] Gardiner, F.J., "The Spring Back of Metals. Transaction of ASME, Jan. 1957, pp. 1-9.

[7] Hosford, W.F. and Caddell, Robert M., "Metal Forming Mechanics and Metallurgy. Englewood Cliffs", N.J. 07632, Prentice-Hall, Inc. 1983.

[8] Kalpajian, Serope, "Manufacturing Engineering and Technology", Illinois Institute of technology, Addison-Welsey Publishing Company, 1989.

[9] Johnson, W. and Mellor, P.B., "Engineering Plasticity", London, Van Nostra Reinhold company, 1980.

[10] Taylor, L., Cao, J., Karafillis, A.P. and Boyce, M.C., "Numerical Simulation of Sheet-metal Forming”, Journal of Materials Processing Technology, 1995; Vol. 50, pp. 168-179.

[11] Esat, V., Darendelier, H. and Gocler, M.I., "Finite Element Analysis of Springback in Bending of Aluminium Sheets", Materials \& Design, 2002; Vol. 23, pp. 223-229.

[12] Gere, J.M. and Timoshenko, S.P., "Mechanics of Materials", PWS Publishing Company, 20 Park Plaza, Boston, Ma. 1997.

[13] Dieter, G.E., "Mechanical Metallurgy”, McGraw Hill, Singapore, 1984.

[14] Ryder, G.H., "Strength of Materials", Macmillan, London, 1992. 